\title{
РОССИЙСКИЕ ПРЕДПРИНИМАТЕЛИ НА СОВРЕМЕННОМ ЭТАПЕ ОБЩЕСТВЕННОГО РАЗВИТИЯ: КОЛИЧЕСТВЕННЫЙ АНАЛИЗ
}

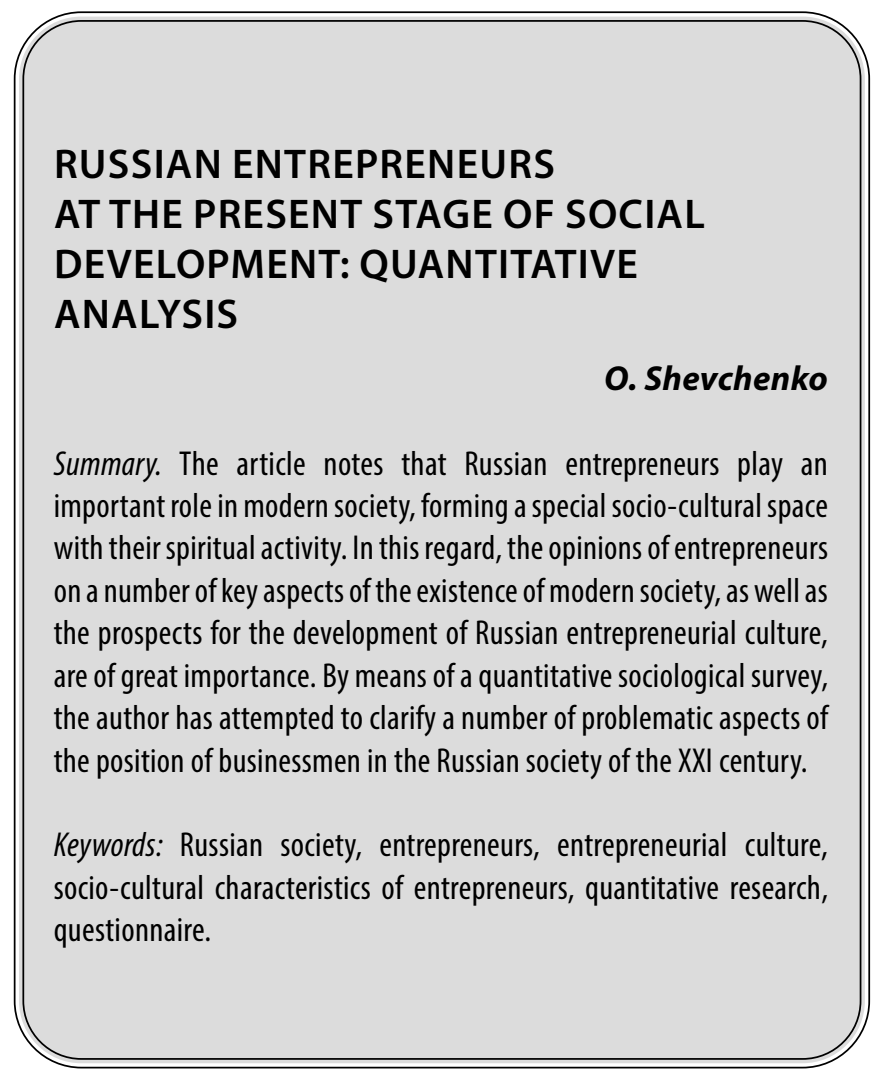

$\mathbf{P}$ оссийские предприниматели являются весьма перспективным объектом социологического познания - как на теоретическом, так и на эмпирическом уровнях. Объясняется это уникальным статусом предпринимателей в социальной системе.

Как отмечает С.С. Котова, «российские предприниматели обладают рядом качеств, которые позволяют говорить о его высокой сопротивляемости неблагоприятным условиям. Это высокий по сравнению с другими социальными группами уровень адаптированности к рыночной экономике, позволяющий реализовывать экономическую стратегию, в которой значительное место принадлежит предпринимательской деятельности и самозанятости. Это высокая социальная мобильность и гибкость, ориентация на максимальное использование своих ресурсов, главными из которых является высокое качество рабочей силы и готовность к дальнейшему повышению стоимости своего «человеческого капитала». Это наличие ряда ценностей, разделяемых подавляющим большинством предпринимателей ориентация на социальное рыночное хозяйство, цен-
Шевченко Ольга Павловна

К.э.н., доцент, Кубанский государственный аграрный университет nikkuban@mail.ru

Аннотация. В статье отмечается, что российские предприниматели в современном социуме играют важную роль, своей духовной активностью образуя особое социокультурное пространство. В этой связи важное значение имеют мнения предпринимателей по ряду ключевых аспектов существования современного общества, а также и перспектив развития российской предпринимательской культуры. Посредством количественного социологического исследования методом анкетирования автор предпринял попытку прояснить ряд проблемных аспектов положения бизнесменов в российском обществе XXI в.

Ключевые слова: российское общество, предприниматели, предпринимательская культура, социокультурные особенности предпринимателей, количественное исследование, анкетирование.

ности индивидуальной свободы, приоритет частной собственности и пр.» [1.С.14].

Анализ различных стадий развития общества (от традиционного до постиндустриального) показывает, что во многих случаях предприниматели оказывались глубоко интегрированы в различные институциональные структуры, выполняя важные функции в социальной системе. Особенно важна роль предпринимателей в современном постиндустриальном обществе XXI в., в котором информация, информационные технологии, интегрированные интернет-коммуникации занимают первостепенное место. Основой глобализации выступает деверсифицированные бизнес-структуры, от транснациональных корпораций до индивидуальных предпринимателей, которые, развивая экономическую подсистему, неизбежно влияют и на остальные политическую, социальную, духовную.

Образ современного предпринимателя ассоциируется у многих как с профессиональными качествами бизнесмена, так и с наличием у него определенного 
культурного и социально значимого потенциала, способного в условиях несбалансированного рынка оказывать активное участие в социальной жизни своего города, региона, государства.[2.С.92-101]

Анализ научной литературы, посвященной сознанию и поведению российских предпринимателей, показал существенный дисбаланс в пользу общетеоретических методов познания. В этой связи автором было принято решение о проведении количественного социологического исследования российских предпринимателей. Общий объем выборки - 1289 человек, в возрасте от 18 лет и старше, занимающиеся бизнесом. Метод исследования - анкетирование. Выборка квотная, неслучайная. Сроки проведения исследования: сентябрь-ноябрь 2021 г.

По данным проведенного исследования, часть респондентов считает, что предприниматели в современном российском обществе играют роль скорее незначительную, чем значительную (28\%) или незначительную $(21,7 \%)$. Примерно такая же доля опрошенных придерживаются противоположной точки зрения по этому вопросу. В частности, видят значительную роль предпринимателей в российском обществе $27,7 \%$, а скорее значительную, чем незначительную - 20,1\% участников исследования. Затруднились ответить на вопрос 2,5\% респондентов. Существенная поляризация мнений предпринимателей по данному вопросу скорее свидетельствует о неоднозначном, противоречивом положении данной социальной группы в обществе. Этому косвенно способствует и объективная обстановка в российском обществе, когда в общественном дискурсе на протяжении с начала 1990-х до настоящего времени отношение к предпринимательскому сообществу менялась кардинально - от «культа» предпринимательства до весьма скептического его восприятия.

Как показало проведенное исследование, несмотря на определенную поляризацию мнений, все же российские предприниматели в целом ощущают себя единым сообществом: вариант «да» отметили 31,8\%, а «скорее да» - 23,6\%. В то же время не ощущают себя единым целым более $40 \%$ опрошенных. Так, вариант «скорее нет» отметили 25,6\%, а «нет» $16,7 \%$ участников исследования. Затруднились ответить на этот вопрос 2,3\% участников исследования. Распределение ответов может свидетельствовать о наличии существенных противоречий внутри предпринимательского сообщества, действии определенных факторов, препятствующих интеграции бизнесменов в единое сообщество. Соответственно, возникают и препятствия для формирования и развития российской предпринимательской культуры. Описание этих препятствий выступает одной из важных задач социологии на современном этапе.
Большинство респондентов считают, что в России можно говорить о наличии предпринимательской культуры. В частности, вариант «да» отметили 37,4\%, а «скорее да» - 30,1\% участников исследования. Порядка трети респондентов в то же время не согласны с данным утверждением: вариант «скорее нет» отметили 18,6\%, а «нет» - 16,7\% респондентов. Затруднились ответить 2,5\% участников исследования. В отношении предпринимательской культуры как социокультурного сегмента российского общества самоощущение предпринимателей имеет существенное значение и в этом аспекте мнения двух третей респондентов о наличии этой культуры весьма важно. В то же время наличие порядка трети респондентов, кто отказывает в существовании предпринимательской культуре, свидетельствует о наличии определенных проблем внутри предпринимательского сообщества, что препятствует более полноценной интеграции.

Ответы респондентов на вопрос «В чем, на Ваш взгляд, проявляется специфика российской предпринимательской культуры» распределились следующим образом. Наиболее распространенная точка зрения: схожие ценности и идеалы (69,2\%), далее - следование единым нормам (53,4\%), а также специфические обычаи и традиции (47,3\%). Менее популярными оказались ответы: особый стиль и образ жизни $(41,1 \%)$, специфическое мироощущение и жизнеощущение (33,8\%), общение в виртуальных сообществах (24,5\%), другое варианты ответа предложили 18,2\% участников исследования. Вариант «все перечисленное» выбрали 12,7\% респондентов. Затруднились ответить 1,8\% участников исследования. Таким образом, опрошенные предприниматели отождествляют культуру своего сообщества именно с тождеством идеалов и ценностей. И действительно, общие целевые установки на ведение бизнеса и положение в социуме могут рассматриваться как достаточно универсальный интегративный потенциал. Вместе с тем, соционормативная модель регуляции бизнеса не обладает таким высоким консолидирующим потенциалом - это продемонстрировало социологическое исследование.

Респонденты отметили в качестве основной характеристики, относящейся к российской предпринимательской культуре, именно стремление к риску (65,3\%). Далее со значительным отрывом следуют: меценатство $(41,4 \%)$, показное престижное потребление $(40,2 \%)$, особые установки по отношению к государству и обществу (34,8\%). Еще реже упоминались такие характеристики как жажда наживы (23,9\%), единая мораль (10,5\%), особые ценности и нормы (7,6\%). Вариант «другое» был упомянут в 5,6\% случаев. Затруднились ответить $2,8 \%$ участников исследования. Весьма примечательно, что большинство опрошенных указали на стремление к риску как атрибу- 
тивную характеристику российской предпринимательской культуры. При этом ценности и идеалы, о которых респонденты рассуждали как интегративном факторе применительно к предпринимательской культуре, в российской реальности практически не работает (лишь 7,6\% ответов). Следовательно, участники исследования рассуждали о ценностях как «идеальном типе», к которому необходимо стремиться в целях институционализации предпринимательской культуры. Также обращает на себя внимание противоречивость характеристик российской предпринимательской культуры - наряду с меценатством упоминается престижное, показное потребление и жажда наживы. Это свидетельствует об амбивалентности образа предпринимательской культуры в представлениях опрошенных.

В результате исследования выяснилось, что большинство респондентов не слишком осведомлены об истории российского предпринимательства. В частности, вообще не знают историю предпринимательства $11 \%$ участников исследования, а 51,5\% указали, что не уверены в этом. Лишь каждый третий опрошенный отметил, что знает историю российского предпринимательства (34,4\%). Еще 3,1\% респондентов затруднились ответить на этот вопрос.

Выявленная закономерность может рассматриваться в качестве одного из тормозящих факторов в аспекте генезиса и развития предпринимательской культуры. Известно, что подобные локальные культурные формы возникают и поддерживаются, едва ли не в первую очередь, посредством связи современности с историческим прошлым. В этом аспекте российская предпринимательская культура находится еще на начальном этапе развития.

Респонденты видят два основных способа культурной трансмиссии применительно к предпринимательской среде. Чаще всего упоминали социализацию и воспитание (61,9\%), а также опыт, практику ведения бизнеса (57,6\%). Остальные варианты оказались гораздо менее востребованы в среде опрошенных. Так, в пользу Интернета как средства передачи предпринимательской культуры из поколения в поколение высказались 46,3\% участников исследования. Примерно четверть опрошенных склонны рассматривать в качестве способов передачи предпринимательской культуры СМИ и кинематограф (26,8\%). Другие варианты ответа предложили 11,9\% участников исследования, а 3,3\% из них затруднились дать содержательный ответ на данный вопрос. Обращает на себя внимание достаточно традиционный «набор инструментов» трансмиссии предпринимательской культуры, а также незначительное внимание, уделенное опрошенными информационно-компьютерным технологиям и Интернету. Достаточно редко упоминались в данном аспекте и виртуальные сообщества предпринимателей. Это свидетельствует о весьма консервативном мышлении российских предпринимателей, что контрастирует с реалиями информационного общества XXI в.

Подавляющее большинство респондентов осведомлены о наличии виртуальных сообществ российских предпринимателей (79,2\%). Лишь 15,5\% участников исследования ничего не знают о таких объединениях, а еще 5,3\% респондентов затруднились ответить на этот вопрос. Вместе с тем, осведомленность о наличии подобных сетевых объединений российских предпринимателей не изменяет сознание опрошенных в аспекте отождествления данных объединений с трансформирующимися формами предпринимательской культуры в XXI в.

В настоящее время 58,4\% опрошенных предпринимателей состоят в корпоративных виртуальных сообществах. Еще 16,3\% респондентов указали, что состояли ранее в таких сообществах, но теперь не состоят. В то же вея $126,6 \%$ участников исследования отметили, что никогда не состояли и е состоят в подобных сообществах. Весьма высокой оказалось и доля тех, то затруднился ответить на этот вопрос - 8,7\%, что свидетельствует о сложности или противоречивости вопроса для сознания респондентов.

Опрошенные предприниматели характеризуются немалым скепсисом в отношении перспектив развития бизнеса в условиях современной России. В частности, подавляющее большинство респондентов - 71,4\% убеждены, что эти перспективы весьма средние. Кроме того, 14,5\% участников исследования ответили, что подобные перспективы однозначно плохие. Оптимистами являются лишь 4,5\% участников исследования, которые уверены в отличных перспективах развития бизнеса. Еще 7,1\% респондентов отметили вариант «хорошие». Затруднились ответить $2,4 \%$ участников исследования.

Таким образом, предприниматели представляют собой особую группу, которая играет важную роль не только в социально-экономической, но и политической, духовной сферах социума. Особенно важна роль предпринимателей в условиях рыночной или смешенной экономической модели, однако и в другие исторические периоды влияние бизнеса на различные сферы и подсистемы общества в определенной мере проявлялось. Социальный и социокультурный вес предпринимательства объясняется тем, что именно эту социальную группу отличает инициатива, стремление к инновациям, что наряду с производством материальных благ, ресурсов позволяет прямо или косвенно удовлетворять различные фундаментальные потребности общества. Объективные характеристики предпринимателей как социальной группы позволяют выявить 
у них и сходные социокультурные черты (ценности, мировоззрение, мироощущение, нормы, идеологии и т.п.), что создает основы для особой предпринимательской культуры как элемента системы культуры социума.

Социологическое исследование, проведенное методом анкетирования, показало, что, несмотря на наличие очевидных дифференцирующих факторов в рамках предпринимательского сообщества современной России, имеется немало жизненно-стилевых, нормативных, аксиологических и иных объединяющих факторов, позволяющих охарактеризовать предпринимательскую культуру с различных аспектов. Ситуация исследования осложнялась нежеланием части предпринимателей идти на контакт с социологом, давать откровенные ответы. Как представляется, противоречивость предпринимательской культуры в современном российском обществе связана с особенностями генезиса и развития данного социокультурного объединения. Для более детальной верификации полученной информации целесообразно провести качественное социологическое исследование.

При разработке программы и инструментария эмпирического исследования следует также принимать во внимание то обстоятельство, что информационное общество посредством информационно-компьютерных технологий меняет облик предпринимательской культуры, в то же время, и сама предпринимательская культура оказывает определенное воздействие на социум XXI в., расширив свои трансляционные возможности на массовую аудиторию. На внешнем уровне взаимодействия предпринимательской культуры и информационного общества имеет место «оцифровка» культурных форм (меняется их привычный облик), а на внутреннем, вследствие виртуализации, серьезно трансформируется и содержание ценностных ориентаций, норм, идеалов, морально-нравственных принципов, мировоззренческих оснований и т.п., составляющих основу предпринимательской культуры. Окончательный ответ на данный вопрос должно дать сравнительное количественно-качественное эмпирическое исследование. Также важное знание имеет поиск первичной социологической информации по следующим блокам:

- какая из идеологий ближе всего;

к каковы жизненные цели, что хотят достичь;

отношение к религии;

- стиль жизни;

- мироощущение.

\section{ЛИТЕРАТУРА}

1. Котова С.С. Российское предпринимательство как предмет социологического анализа: дис. ... канд. соу. наук. М., 2003.

2. Никонов В.А. Характеристика российского предпринимателя в зеркале общественного мнения // Известия высших учебных заведений. Поволжский регион. Общественные науки. 2017. № 2.

(c) Шевченко Ольга Павловна ( nikkuban@mail.ru ).

Журнал «Современная наука: актуальные проблемы теории и практики» 